\title{
Direct and semi-direct radiative forcing of smoke aerosols over clouds
}

\author{
E. M. Wilcox \\ Desert Research Institute, Reno, Nevada, USA \\ Correspondence to: E. M. Wilcox (eric.wilcox@dri.edu) \\ Received: 4 June 2011 - Published in Atmos. Chem. Phys. Discuss.: 25 July 2011 \\ Revised: 12 December 2011 - Accepted: 18 December 2011 - Published: 3 January 2012
}

\begin{abstract}
Observations from Earth observing satellites indicate that dark carbonaceous aerosols that absorb solar radiation are widespread in the tropics and subtropics. When these aerosols mix with clouds, there is generally a reduction of cloudiness owing to absorption of solar energy in the aerosol layer. Over the subtropical South Atlantic Ocean, where smoke from savannah burning in southern Africa resides above a persistent deck of marine stratocumulus clouds, radiative heating of the smoke layer leads to a thickening of the cloud layer. Here, satellite observations of the albedo of overcast scenes of $25 \mathrm{~km}^{2}$ size or larger are combined with additional satellite observations of clouds and aerosols to estimate the top-of-atmosphere direct radiative forcing attributable to presence of dark aerosol above bright cloud, and the negative semi-direct forcing attributable to the thickening of the cloud layer. The average positive direct radiative forcing by smoke over an overcast scene is $9.2 \pm 6.6 \mathrm{~W} \mathrm{~m}^{-2}$ for cases with an unambiguous signal of absorbing aerosol over cloud in passive ultraviolet remote sensing observations. However, cloud liquid water path is enhanced by $16.3 \pm 7.7 \mathrm{~g} \mathrm{~m}^{-2}$ across the range of values for sea surface temperature for cases of smoke over cloud. The negative radiative forcing associated with this semi-direct effect of smoke over clouds is estimated to be $-5.9 \pm 3.5 \mathrm{~W} \mathrm{~m}^{-2}$. Therefore, the cooling associated with the semi-direct cloud thickening effect compensates for greater than $60 \%$ of the direct radiative effect. Accounting for the frequency of occurrence of significant absorbing aerosol above overcast scenes leads to an estimate of the average direct forcing of $1.0 \pm 0.7 \mathrm{~W} \mathrm{~m}^{-2}$ contributed by these scenes averaged over the subtropical southeast Atlantic Ocean during austral winter. The regional average of the negative semi-direct forcing is $-0.7 \pm 0.4 \mathrm{~W} \mathrm{~m}^{-2}$. Therefore, smoke aerosols overlaying
\end{abstract}

the decks of overcast marine stratocumulus clouds considered here yield a small net positive radiative forcing, which results from the difference of two larger effects.

\section{Introduction}

Radiative forcing by aerosols owing to the scattering of shortwave solar radiation is presently offsetting a portion of the warming of climate attributable to the rise in atmospheric greenhouse gas concentrations (Forster et al., 2007). While considerable uncertainty surrounds estimates of the magnitude of the aerosol radiative forcing, the consequences of the forcing include variations in surface solar insolation (Wild 2009) and changes in the hydrologic cycle (Ramanathan et al., 2001).

In cases where absorbing aerosols mix within a layer of low cloud, there is often a reduction in cloud cover yielding a positive radiative forcing of climate (Hansen et al., 1997; Ackerman et al., 2000; Kaufman and Koren, 2006). This so-called semi-direct forcing results from the heating of the mixed smoke-cloud layer owing to the absorption of solar radiation by the aerosols. The additional heat from aerosol absorption reduces the relative humidity of the layer thereby promoting the evaporation of clouds. The positive climate forcing results from the reduction of bright cloud exposing a darker surface underneath. However, when the absorbing aerosol resides above a low cloud deck the absorption of sunlight by the aerosols causes a reduction in cloud-top entrainment that leads to a thickening of the cloud deck (Wilcox, 2010; Johnson et al., 2004). Thicker clouds are, in general, brighter, thus yielding a negative radiative forcing. This negative semi-direct forcing expected from the thickening of the 
cloud layer is in addition to the direct radiative forcing of the aerosol.

Over the ocean, the direct radiative forcing of absorbing aerosol over an overcast scene is positive owing to darkening of the bright cloud scene by the overlying dark aerosol particles. The direct forcing shifts to negative as the cloud cover underneath decreases and the scattering by aerosols brightens the dark ocean scene (Chand et al., 2009; Podgorny and Ramanathan, 2001). In this study the magnitudes of the direct and semi-direct radiative effects of aerosols are estimated using a combination of NASA A-Train satellite observations for cases where absorbing smoke aerosols reside above overcast decks of stratocumulus clouds. The goal of this study is to compare the magnitude of the positive direct radiative forcing to the compensating negative forcing owing to the semi-direct thickening of the cloud layer.

Seasonal burning of the southwestern African Savannah produces a persistent layer of dark smoke over the southeast Atlantic Ocean during the austral winter and spring. The layer is present each year and is the consequence of episodic transport events that carry smoke plumes from the interior plains out over the ocean (Swap et al., 1996). Figure 1 shows the resulting broad plume of aerosol over the ocean indicated by a substantial ultraviolet absorption signature detectible in the Ozone Monitoring Instrument (OMI) satellite dataset. Beneath the elevated layer of smoke is a persistent deck of bright marine stratocumulus cloud. Field measurements have verified that the smoke is substantially absorbing in the ultraviolet (UV) and visible wavelengths (Haywood et al., 2004), meaning that both the downward incident solar radiation from above, and the upward reflected solar radiation from the cloud-top below are substantially attenuated as solar energy is deposited in the smoke layer.

Wilcox (2010) has shown that the absorption of solar energy in the southeast Atlantic Ocean smoke layer leads to temperatures in the $700 \mathrm{hPa}$ layer of the atmosphere above the stratocumulus cloud deck that are warmer by $1 \mathrm{~K}$ when smoke is present above the cloud layer compared to cases without smoke above the cloud deck. The clouds beneath the smoke layer exhibit cloud liquid water path (LWP) amounts that are greater by $20 \mathrm{~g} \mathrm{~m}^{-2}$ and cloud tops that are lower compared to clouds without overlaying smoke. These observations confirm the large-eddy simulation results obtained by Johnson et al. (2004), where it is argued that warming by absorption of solar energy above the cloud increases the buoyancy of the air above the temperature inversion that caps the cloud-topped marine boundary layer. The increase in buoyancy inhibits entrainment of dry air from the freetroposphere across the cloud top, preserving boundary layer relative humidity and causing thicker clouds with greater LWP and a lower cloud top altitude than cases without absorbing smoke above the cloud. Radiative transfer model calculations in Wilcox (2010) demonstrate that the radiative heating by smoke aerosols above clouds is sufficient to explain the warmer temperatures observed in the smoke layer,

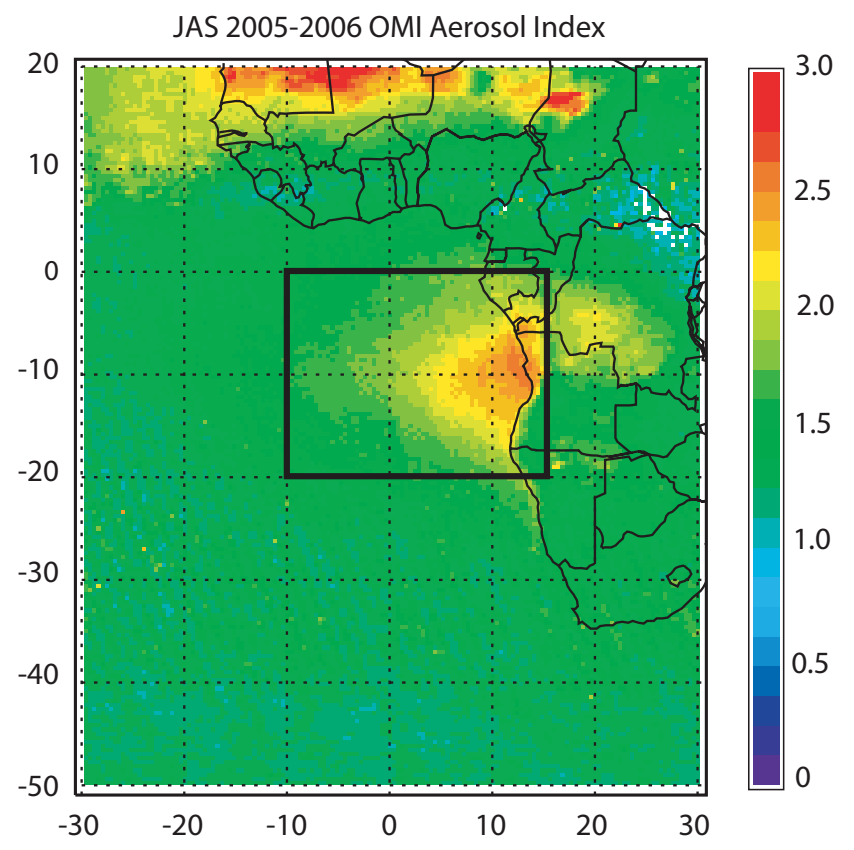

Fig. 1. 2005-2006 July, August, and September average OMI aerosol index (from: Wilcox et al., 2009).

and exceed the warming from horizontal temperature advection or subsidence during episodes of smoke loading over the southeast Atlantic Ocean.

\section{Satellite data and methods of analysis}

The empirical relationship between cloud albedo and LWP determined from satellite observations of overcast scenes is used in this study to estimate, separately, the direct radiative forcing of smoke above stratocumulus clouds assuming that the cloud layer is unchanged by the smoke, and the semidirect radiative forcing attributable to the cloud thickening reported in Wilcox (2010). The albedo of water clouds is largely determined by the total amount of water in the cloud (quantified with the LWP). The presence of absorbing smoke above a bright cloud reduces the albedo of the scene owing to the attenuation of the downwelling and upwelling solar radiation in the aerosol layer. The difference in observed cloud albedo, for a given LWP, between scenes with smoke above cloud and scenes without smoke above cloud is used to deduce the positive direct radiative forcing owing to the darkening of the overcast scenes by overlaying smoke. The negative forcing attributable to the thickening of clouds beneath smoke observed by Wilcox (2010) is estimated from the observed dependence of cloud albedo upon LWP. For both effects, the forcing is calculated as the product of the diurnal mean solar insolation and the difference in albedo between scenes effected by smoke and those not effected by smoke. 
The presence of smoke above clouds is determined using the aerosol index (AI) based on ultraviolet reflectance measurements from the Ozone Monitoring Instrument (OMI; Herman et al., 1997; Torres et al., 2007). Cloud albedo is obtained from the Clouds and the Earth's Radiant Energy System (CERES) broadband radiometer sensor which measures reflected solar radiance in the 0.3 to $5 \mu \mathrm{m}$ spectral range (Wielicki et al., 1996). LWP is obtained from the Advanced Microwave Scanning Radiometer-EOS (AMSR-E) sensor (Wentz 1997; Wentz and Spencer, 1998) based on the microwave emission signature of liquid water clouds. Additional screening of the data for overcast conditions is performed using the visible and near-infrared cloud-top properties retrieved with the Moderate Resolution Imaging Spectroradiometer (MODIS) sensor (Platnick et al., 2003). The CERES, AMSR-E and MODIS instruments are on the Aqua satellite and the OMI instrument is on the Aura satellite. The Aura satellite follows the Aqua satellite in the same orbit approximately 15 minutes behind. Both are elements of the NASA A-Train satellite constellation. All data are taken from the daytime pass of the A-Train satellites (approximately 1:30 p.m. local time).

All satellite data are obtained for the oceanic region offshore of southern Africa bounded by $10^{\circ} \mathrm{W}$ to $15^{\circ} \mathrm{E}$ longitude and $20^{\circ} \mathrm{S}$ to $0^{\circ} \mathrm{S}$ latitude during July, August, and September (JAS) for the years 2005 and 2006. Instantaneous AMSR-E LWP and OMI AI data are obtained for each orbit averaged in space on a $0.25^{\circ}$ lat.-lon. grid. Level-2 MODIS cloud pixel data are obtained at $1 \mathrm{~km}$ resolution and used to screen for overcast conditions as described below. CERES cloud albedo data are obtained at pixel resolution (approx. $20 \mathrm{~km}$ at nadir). The albedo of each $0.25^{\circ}$ grid cell is determined from the average of all CERES pixels with center points located within the grid cell. Uncertainty in the instantaneous shortwave flux at the top-of-atmosphere for cloudysky mid-latitude scenes is estimated to be approximately $4 \%$, and does not vary significantly with cloud optical depth or cloud fraction in liquid water clouds (Loeb et al., 2007).

The AMSR-E passive microwave retrievals of LWP are used rather than the visible/near infrared retrievals based on MODIS observations because of a bias in the MODIS observations that is specific to cases where absorbing aerosol resides above cloud. A low bias in the retrieved cloud optical thickness from MODIS occurs for cases with smoke above clouds owing to the absorption by the smoke in the $0.86 \mu \mathrm{m}$ band used in the optical thickness retrieval (Haywood et al., 2004). This results in a bias in the mean MODIS-derived LWP, (which is derived from the cloud optical thickness) in this region of $5.6 \mathrm{~g} \mathrm{~m}^{-2}$ that increases with OMI AI and smoke aerosol loading above cloud (Wilcox et al., 2009). For this reason, it is not appropriate to diagnose changes in LWP attributable to absorbing aerosol above cloud using the MODIS retrievals.

The AMSR-E gridded LWP is an average over the entire $0.25^{\circ}$ area, including clear-sky portions of the grid cell.
Therefore, the overcast LWP can only be obtained for grid cells confidently determined to be overcast. Because cloud thickening will be diagnosed by changes in LWP, and differences in LWP between broken cloud scenes can occur either because of differences in the thickness of the cloud layer or differences in cloud fraction, a stringent test for overcast conditions is made to isolate the thickening effect. Except where noted, only overcast grid cells are used in the analysis. This overcast screening is the same as applied operationally in the level-2 1-km MODIS visible/near-infrared cloud optical thickness and cloud drop effective radius product (Platnick et al., 2003). In practice, the overcast screening is applied by only using grid cells completely spanned by MODIS $1-\mathrm{km}$ footprints with valid retrievals of cloud optical thickness and cloud drop effective radius flagged as "confident". This conservative screening for overcast conditions captures only about $40 \%$ of the overall cloud cover because there are many clouds that are smaller than a grid cell. However, there remain greater than 36,000 overcast grid cells with valid coincident albedo, LWP, and OMI AI values in two years of daytime satellite overpasses during the JAS period.

The OMI AI is used as an indicator of the magnitude of absorption by smoke aerosols occurring above the cloud. The goal is to compare the magnitude of the direct radiative effect to that of the semi-direct effect for similar aerosol absorption in the layer above the cloud. The OMI AI increases with the amount of smoke residing in the column and may be retrieved even for overcast conditions (Hsu et al., 1996; Torres et al., 1998; Torres et al., 2007). OMI AI is zero in the absence of aerosols and increases approximately linearly with the UV absorption optical depth. OMI AI values within the domain of interest vary from -1.5 to greater than 5 , where values less than zero may indicate the presence of scattering aerosols and the positive values indicate the presence of absorbing aerosols.

In addition to the optical thickness of aerosols, the magnitude of the AI above clouds also depends on the optical properties of the aerosols, the vertical distribution of the aerosols, and the optical thickness of the clouds beneath the aerosols. The uncertainty in interpreting the OMI AI as a proxy for the optical thickness of smoke above cloud owing to these other quantities that influence the resulting OMI AI can be estimated from the results of Torres et al. (2011). The dependence of OMI AI on the aerosol layer height is $0.55 \mathrm{~km}^{-1}$ in Fig. 4 of Torres et al. (2011) for an absorbing aerosol layer above a cloud of optical thickness 10 . Sixty seven percent of aerosol layers present above clouds in the Calipso lidar dataset reside between 2.8 and $3.7 \mathrm{~km}$ altitude (1-sigma variability derived from the histograms in Fig. 1 of Wilcox, 2010). This is an uncertainty owing to variability in aerosol layer height of \pm 0.25 . The dependence of OMI AI on the optical thickness of the cloud beneath the aerosol is less than 0.05 per unit cloud optical thickness for a layer of aerosol optical thickness 1 , single-scattering albedo 0.85 and absorption Angstrom exponent 1.91 residing above a cloud 

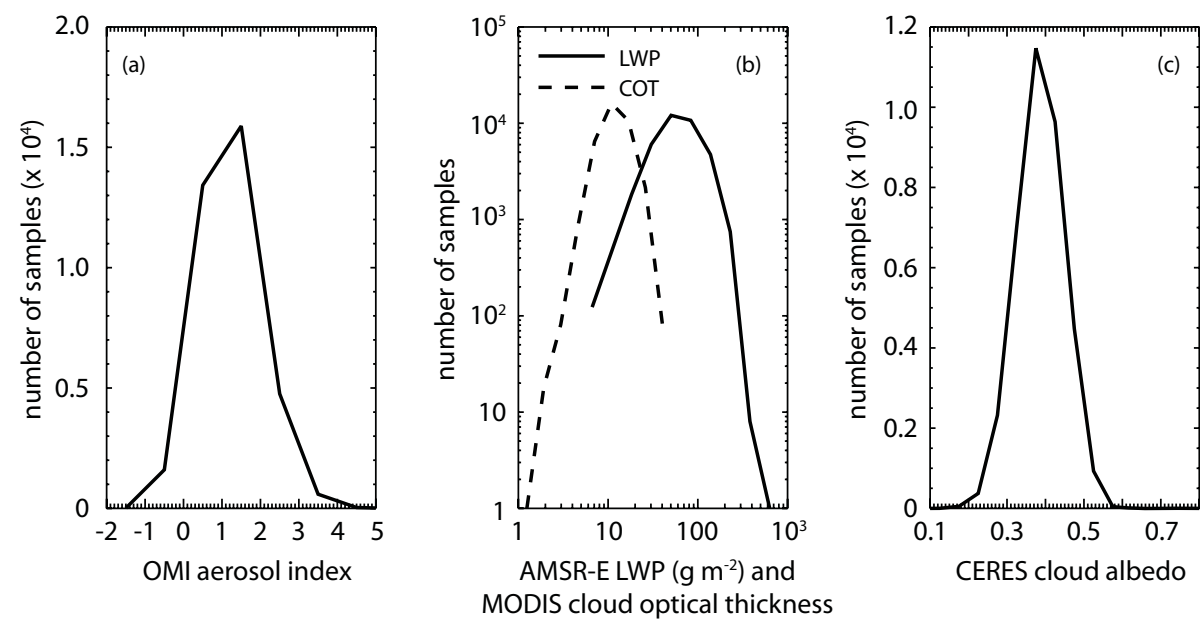

Fig. 2. Histograms of the number of overcast samples against (a) OMI AI, (b) AMSR-E LWP (solid line) and MODIS cloud optical thickness (COT; dashed line), and (c) CERES cloud albedo. The total number of samples in each histogram is 36304 .

of optical thickness 10 (Fig. 3 in Torres et al., 2011). Sixty seven percent of overcast cloud samples fall between cloud optical thickness values of 8 and 16 (1-sigma variability in optical thickness). This is an uncertainty in OMI AI owing to cloud optical thickness variability of \pm 0.2 . Since the OMI AI is determined from the spectral difference in UV reflectance, a relevant optical property of the aerosols is the absorption angstrom exponent (AAE). The dependence of OMI AI on the AAE is at most 1.31 per unit AAE in Fig. 3 of Torres et al. (2011) for a layer of aerosol above a cloud of optical thickness 10. Russell et al. (2010) report that the global range of AAE values for biomass burning sources is from 1.25 to 1.75 . Using this as a plausible range of variability in smoke AAE in the southeast Atlantic region implies an uncertainty in OMI AI of \pm 0.33 . Assuming these three sources of uncertainty in the interpretation of OMI AI as an indicator of aerosol amount are uncorrelated, the total uncertainty in OMI AI as applied in this study is \pm 0.46 .

This paper does not attempt to determine the radiative forcing efficiency (i.e. the forcing as a function of aerosol optical thickness) from the satellite data. Quantitative retrievals of the aerosol optical thickness in the visible are available over cloud using the CALIOP satellite lidar data (Chand et al., 2008) and the POLDER measurements of polarized radiance (Waquet et al., 2009). In future work, these data could be employed to estimate the direct and semi-direct forcing efficiency above clouds. The OMI AI is used here because of the superior spatial sampling of the scanning radiometer compared to the linear sampling of CALIOP, the extensive existing literature documenting its properties, and its availability across the Aura satellite period. OMI AI values greater than 1 are adopted in this study as an indication of the presence of absorbing aerosol above cloud. The forcing for overcast scenes with OMI AI $>1$ (as well as AI values greater than other integer values of $\mathrm{AI}$ ) is estimated relative to scenes with OMI $\mathrm{AI} \leq 0$, which is an indication that absorbing aerosols are not present above the cloud. Note that some scenes with negative values of OMI AI may include bright scattering aerosols, and therefore may not be "clean" scenes. However, the goal of the study is to evaluate the effects of absorbing smoke aerosols over clouds, rather than that of all aerosols. Based on the uncertainties noted above, it is determined that using the OMI AI in this fashion is sufficient to compare the direct and semi-direct radiative effects for the same level of aerosol absorption occurring above the cloud. Further evidence of a monotonic increase in the influence of smoke aerosols with increasing OMI AI on the transmission of visible light through the atmosphere over the Southeast Atlantic Ocean is presented in Wilcox et al. (2009).

A summary of observing systems used in this study appears in Table 1, including values of reported uncertainties in instantaneous parameter retrievals from the literature estimated from the RMS error of retrievals performed at instrument resolution.

Histograms of OMI AI, AMSR-E LWP, MODIS cloud optical thickness, and CERES cloud albedo are shown in Fig. 2 for overcast conditions in the southeast Atlantic Ocean domain indicated by the box in Fig. 1. The number of OMI AI values greater than integer thresholds of OMI AI from 0 to 5 is summarized in Table 2.

\section{Direct radiative warming of smoke over clouds}

The albedo of overcast liquid water cloud scenes increases with increasing LWP. This is illustrated in Fig. 3 where the albedo of all overcast scenes is averaged in LWP bins spanning a range from less than $10 \mathrm{~g} \mathrm{~m}^{-2}$ to greater than $650 \mathrm{~g} \mathrm{~m}^{-2}$. Cloud albedo increases from 0.2 to nearly 0.6 across the LWP range. The relationship between albedo and 
Table 1. Data sources.

\begin{tabular}{lllll}
\hline Parameter & Sensor & Platform & units & uncertainty \\
\hline Aerosol index & OMI & Aura & non-dimensional & $0.46^{*}$ \\
Upwelling shortwave flux & CERES & Aqua & $\mathrm{W} \mathrm{m}^{-2}$ & $3 \%{ }^{* *}$ \\
LWP & AMSR-E & Aqua & $\mathrm{g} \mathrm{m}^{-2}$ & $25 \mathrm{~g} \mathrm{~m}^{-2}$ (random) \\
Cloud cover & MODIS & Aqua & non-dimensional & $\begin{array}{l}5 \mathrm{~g} \mathrm{~m}^{-2} \text { (systematic) } \\
\text { conservative overcast*** }\end{array}$ \\
\hline
\end{tabular}

Estimated uncertainties reported for the retrieved parameter at instrument resolution. ${ }^{*}$ See discussion in Sect. $2 .{ }^{* *}$ Loeb et al (2007); ${ }^{* * *}$ Wentz (1997). CERES uncertainty is treated as systematic. ${ }^{* * * *}$ See discussion in section 2 for methods of applying a conservative threshold for overcast conditions.

Table 2. Summary of sample sizes for scenes with valid retrievals of albedo, LWP and OMI AI.

\begin{tabular}{cllllllll}
\hline Sample description & Valid retrievals & Overcast & $\mathrm{AI}>0$ & $\mathrm{AI}>1$ & $\mathrm{AI}>2$ & $\mathrm{AI}>3$ & $\mathrm{AI}>4$ & $\mathrm{AI}>5$ \\
\hline$N$ & 188465 & 36304 & 34681 & 21265 & 5383 & 622 & 35 & 1 \\
\hline
\end{tabular}

LWP is shown separately for samples with OMI AI greater than 2, OMI AI between 0 and 2, and OMI AI less than 0 . The albedo of scenes with OMI AI $>2$ (red curve) is lower than those in the lower OMI AI curves with the same value of LWP for all scenes with LWP greater than $20 \mathrm{~g} \mathrm{~m}^{-2}$. The reduction in albedo at constant LWP for increasing OMI AI indicates the reduction in upwelling solar energy owing to the absorption by the smoke.

The difference between the curves shown in Fig. 3 is used to estimate the direct radiative forcing of smoke over clouds. The average of the local radiative forcing $\left(\overline{F_{d}}\right)$ of all $\mathrm{N}_{\mathrm{AI}>2}$ overcast scenes with OMI AI $>2$ relative to the scenes with $\mathrm{OMI} \mathrm{AI} \leq 0$ is computed as:

$\overline{F_{d}}=\frac{1}{N_{\mathrm{AI}>2}} \sum S_{0}\left(\left|\alpha_{\mathrm{AI} \leq 0}\right\rangle-\alpha_{\mathrm{AI}>2}\right)$

where $S_{0}$ is the diurnal-mean solar insolation appropriate for the latitude and season of the sample, $\alpha_{\mathrm{AI}>2}$ is the observed albedo of the scene, and $\left\langle\alpha_{\mathrm{AI} \leq 0}\right\rangle$ is the average albedo of all samples with $\mathrm{AI} \leq 0$ within the same LWP bin as the scene with smoke. This quantity is $13.1 \pm 6.6 \mathrm{~W} \mathrm{~m}^{-2}$, and is the positive radiative forcing resulting from the average deviation of the individual samples contributing to the red curve in Fig. 3 from the blue curve. The local forcing for scenes with OMI AI greater than other thresholds of AI is shown in Fig. 4a. The mean direct forcing for scenes with OMI $\mathrm{AI}>1$ relative to those with $\mathrm{AI} \leq 0$ is $9.2 \pm 6.6 \mathrm{~W} \mathrm{~m}^{-2}$. The uncertainty in the forcing estimates is based on a combination of the standard deviation of the mean in the observed albedo within LWP bins and the reported uncertainty in instantaneous CERES albedos (Table 1). Note that by using the diurnal-mean solar insolation, these estimates are for the diurnal-mean radiative forcing. However the satellite cloud albedo observations are for the 1:30 p.m. local time overpass of the satellite, therefore these estimates do not account for

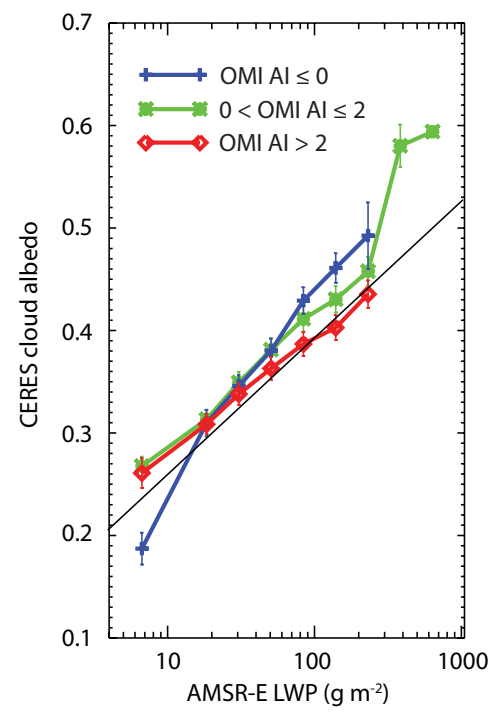

Fig. 3. CERES Cloud albedo against AMSR-E LWP for different quantities of OMI AI. Error bars are based on a combination of the standard deviation of the mean of the albedo samples in each LWP bin and the reported $3 \%$ uncertainty in the instantaneous CERES albedo values (Table 1). The narrow line indicates the leastsquares linear fit based on all individual samples with OMI AI $>1$. Slope $\frac{\partial \alpha}{\partial \log }(\mathrm{LWP})$ is $0.133 \pm 0.001$ (1-sigma uncertainty in the leastsquares fit).

the solar zenith angle variability of cloud albedo through the sunlit hours of the day.

The mean local forcing increases to nearly $30 \mathrm{~W} \mathrm{~m}^{-2}$ for the average of all samples with OMI AI $>4$. Only one sample was found with OMI AI greater than 5. The number of overcast samples exceeding each integer value of OMI AI is listed in Table 2 along with the total number of samples with 

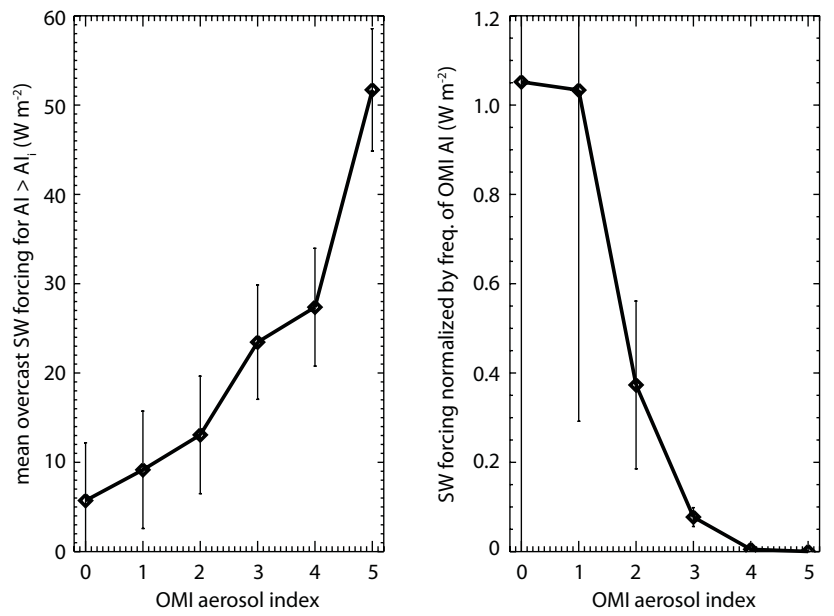

Fig. 4. (a) Diurnal-mean shortwave radiative forcing at the top of the atmosphere averaged over overcast scenes greater than the OMI AI value on the abscissa; and (b) the same normalized by the frequency of occurrence of OMI AI. Uncertainties are based on a combination of the standard deviation of the mean in the observed albedo within LWP bins and the reported uncertainty in instantaneous CERES albedos (Table 1).

valid retrievals and the number of those that are confidently identified as overcast. While the positive forcing is larger for overcast scenes with values of OMI AI greater than 4, these conditions occur so rarely that the mean forcing over the entire region and season attributable to these samples is negligible.

In Fig. $4 \mathrm{~b}$ the local forcing values (and their uncertainties) from Fig. 4a have been multiplied by the fraction of the total number of valid samples that are overcast and have an OMI AI value that exceeds the AI value on the abscissa. This yields an estimate of the mean direct radiative forcing over the entire domain attributable to smoke above overcast scenes. The mean forcing over the domain attributable to the samples with OMI AI $>1$ is $1.0 \pm 0.7 \mathrm{~W} \mathrm{~m}^{-2}$. The same for samples with OMI AI $>2$ is $0.4 \pm 0.2 \mathrm{~W} \mathrm{~m}^{-2}$. Because the technique employed here requires overcast scenes and the spatial resolution of the data is rather coarse, the forcing reported here ignores a large number of partly cloudy scenes, some of which also exhibit smoke over clouds. For this reason, the domain-averaged forcing estimated here is almost certainly an underestimate. Indeed, Chand et al. (2009) estimate that the direct radiative forcing for the July to October period over the same region is $2.4 \mathrm{~W} \mathrm{~m}^{-2}$. The strict screening of overcast conditions applied here captures about $40 \%$ of the total cloud cover and $44 \%$ of the total reflected solar energy over the entire sample period and region. Without finer scale observations of albedo and overcast LWP it is not possible to estimate the direct and semi-direct forcing using the methods described here for clouds smaller than about $25 \mathrm{~km}^{2}$ in horizontal scale. However, this approach does al- low for the direct comparison of the magnitude of the direct radiative warming of smoke over clouds to the semi-direct radiative cooling as discussed below. A more comprehensive estimate of radiative forcing from direct and indirect effects under cloudy conditions (but not the cloud thickening effect) for the entire Atlantic Ocean and other seasons is provided by Peters et al. (2011) using similar data. They estimate a positive regional forcing of $1.55 \pm 0.7 \mathrm{~W} \mathrm{~m}^{-2}$ for the JJA season owing to OMI AI $>0.7$, which is somewhat larger than the regional forcing shown in Fig. 4 of the present study, but is a difference that is within the uncertainties reported in both studies.

Simulations with a plane-parallel radiative transfer model (Chou, 1992) confirm that the aerosol observed above clouds does yield the observed difference in albedo at the top of the atmosphere. The model simulates scattering and absorption of shortwave radiation in a single column by aerosols, clouds, ozone, water vapor, oxygen, and carbon dioxide in 75 pressure levels from the surface to the top of the atmosphere. Each layer is approximately $24 \mathrm{hPa}$ thick in the lower and middle troposphere. A half-sinusoidal vertical profile of aerosol optical thickness is applied to the model from 1.5 to $4.2 \mathrm{~km}$ altitude with the peak aerosol concentration at about $3 \mathrm{~km}$ altitude. A uniform layer of cloud is included below the smoke layer from $0.5 \mathrm{~km}$ to $1.25 \mathrm{~km}$ altitude. The smoke and cloud layer characteristics are based on the frequency of occurrence of aerosol and cloud layers in the CALIOP feature mask product (version 3) from the CALIPSO satellite (Wilcox, 2010). The aerosol single-scattering albedo is $0.89 \pm 0.03$ at $0.55 \mu \mathrm{m}$ based on observations from the SAFARI 2000 field campaign (Haywood et al., 2003), and the spectral dependence of the single-scattering albedo is $-0.1 \mu \mathrm{m}^{-1}$ based on the column-integrated surface sun photometer measurements also made during SAFARI 2000 (Eck et al., 2003).

The model calculations show that the albedo at the top of the atmosphere is reduced when smoke is present above the cloud layer and that the albedo reduction depends on the liquid water path of the cloud layer (Fig. 5). The curves converge at LWP of approximately $20 \mathrm{~g} \mathrm{~m}^{-2}$ where the enhanced scattering of the aerosol layer is greater than the reduction in scene brightness owing to absorption. This cross-over point is near to the observed LWP value exhibiting the minimum difference between the albedo curves in Fig. 3 for different levels of OMI AI, indicating that the satellite observations are reflecting the expected relationships between direct radiative forcing and LWP provided by the model calculations. Forcing values owing to the model-simulated albedo reduction of smoke over overcast scenes is shown in Fig. 6. The forcing increases strongly with LWP, but the dependence on LWP begins to level off near the upper bound of the observed values of LWP owing to the saturation of the albedo for thick clouds evident in Fig. 5.

The magnitude of the direct radiative forcing increases with the optical thickness of the aerosol layer (Fig. 6b). The 


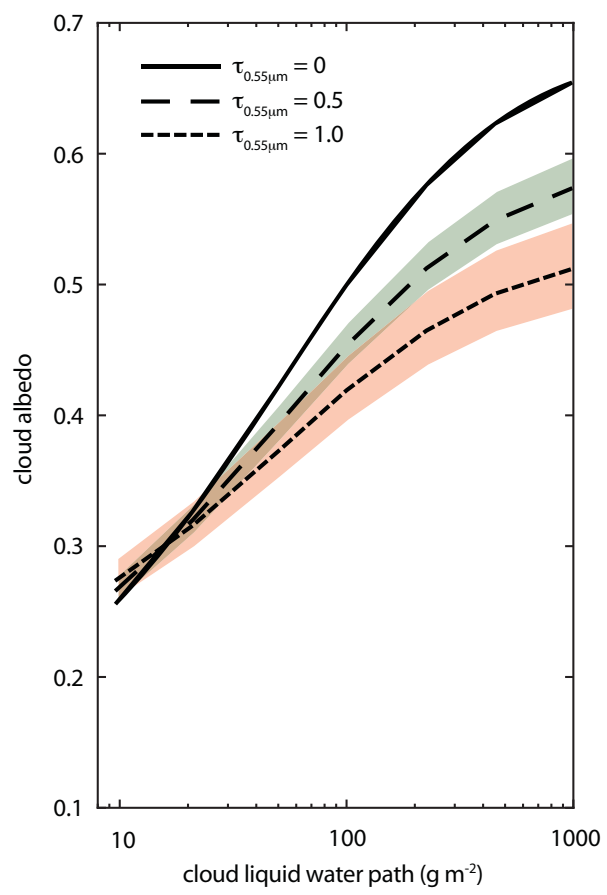

Fig. 5. Albedo for overcast scenes against liquid water path in a radiative transfer model for aerosol layers of 0.5 optical thickness at $0.55 \mu \mathrm{m}$ (dashed), 1.0 optical thickness (dotted), and no aerosols (solid). Color shaded areas bounding each line indicate range of values for \pm 0.03 uncertainty in aerosol single-scattering albedo.

forcing efficiency, i.e. the forcing at the top of the atmosphere for a column containing an aerosol layer of one unit aerosol optical thickness (at $0.55 \mu \mathrm{m}$ wavelength) increases from approximately $18 \pm 8 \mathrm{~W} \mathrm{~m}^{-2} \tau_{0.55}^{-1} \mu \mathrm{m}$ when a cloud of $45 \mathrm{~g} \mathrm{~m}^{-2}$ resides beneath the smoke layer, to as much as $60 \pm 13 \mathrm{~W} \mathrm{~m}^{-2} \tau_{0.55 \mu \mathrm{m}}^{-1}$ for the thickest clouds observed in the AMSR-E dataset. The uncertainties indicate the range of forcing values allowed for an uncertainty of \pm 0.03 in the single-scattering albedo.

\section{Semi-direct radiative cooling by cloud thickening}

Wilcox (2010) finds a systematic difference in LWP of $20 \mathrm{~g} \mathrm{~m}^{-2}$ between cases with OMI AI $>2$ and cases with OMI AI $\leq 1$ across a range of values of sea surface temperature. The observed dependence of overcast cloud albedo upon LWP shown in Fig. 3 is further used to estimate the semi-direct radiative forcing attributable to this cloud thickening effect. Here, using a larger number of samples (owing the relaxation of a constraint on cloud-top temperature used in Wilcox 2010), it is found that the average difference in LWP between samples with OMI AI $>1$ and OMI AI $\leq 0$ is $16.3 \pm 7.7 \mathrm{~g} \mathrm{~m}^{-2}$ and the average difference between samples with OMI AI $>2$ and OMI AI $\leq 0$ is $20.8 \pm 7.9 \mathrm{~g} \mathrm{~m}^{-2}$. Figure $7 \mathrm{a}$ shows the same for all minimum thresholds of OMI
AI from 0 to 4 . The uncertainty in the LWP difference reflects the random and systematic errors in the LWP retrieval (Table 1) and the standard deviation of the mean of the LWP values in the high and low OMI AI populations.

The estimated mean local radiative forcing attributable to the higher value of LWP in the OMI AI >1 samples is computed as:

$\overline{F_{s d}}=\frac{1}{N_{\mathrm{AI}>1}} \sum_{n=1}^{N_{\mathrm{AI}>1}} S_{0} \frac{\partial \alpha}{\partial \log (\mathrm{LWP})}$

$\left[\log \left(\mathrm{LWP}_{n}-\overline{\Delta \mathrm{LWP}_{\mathrm{AI}>1}}\right)-\log \left(\mathrm{LWP}_{n}\right)\right]$

where $\mathrm{N}_{\mathrm{AI}>1}$ is the number of overcast samples with $\mathrm{AI}$ $>1, \mathrm{LWP}_{n}$ is the LWP of a single sample with $\mathrm{AI}>1$, $\log \left(\overline{\Delta \mathrm{LWP}_{\mathrm{AI}>1}}\right)$ is the average difference between samples with OMI AI $>1$ and OMI AI $\leq 0$ given above, and $\left(\frac{\partial \alpha}{\partial \log (\mathrm{LWP})}\right)$ is the slope of the albedo against LWP obtained by linear fit to the entire set of $0.25^{\circ}$ overcast samples with OMI AI $>1$. The slope of albedo against $\log (\mathrm{LWP})$ is $0.133 \pm 0.001$, where the uncertainty is the 1-sigma error in the least-squares fit to the full set of 21266 overcast samples with a valid retrievals of albedo, LWP, and OMI AI $>1$. Limiting the slope calculation to the samples with OMI AI $>1$ accounts for the fact that the enhance LWP attributable to the smoke above the cloud yields a slightly muted increase in cloud albedo at the top of the atmosphere because of the attenuation of the reflected solar energy in the smoke layer. Computed in this fashion, the resulting forcing for cases with smoke over clouds is the difference between the local overcast cloud radiative forcing were the observed LWP reduced by $\overline{\Delta \mathrm{LWP}_{\mathrm{AI}>1}}$ and the observed cloud radiative forcing. The mean local radiative forcing computed using (2) for the change in LWP observed between the OMI AI $>1$ and $\mathrm{OMI} \mathrm{AI} \leq 0$ samples is $-5.9 \pm 3.5 \mathrm{~W} \mathrm{~m}^{-2}$. The forcing for the LWP difference between the OMI AI $>2$ and OMI $\mathrm{AI} \leq 0$ samples is $-6.8 \pm 4.0 \mathrm{~W} \mathrm{~m}^{-2}$. Forcing values for all thresholds of minimum OMI AI from 0 to 4 are shown in Fig. 7b. For the OMI AI $>1$ scenes, the negative semi-direct radiative forcing owing to cloud thickening compensates for greater than $60 \%$ of the positive direct radiative forcing of $9.2 \mathrm{~W} \mathrm{~m}^{-2}$ shown in Fig. 4a. The uncertainty in the forcing accounts for the random and systematic errors in the LWP retrieval (Table 1) and uncertainty in the slope $\frac{\partial \alpha}{\partial \log (\mathrm{LWP})}$. Although absorbing smoke above an overcast scene darkens the appearance of a cloud owing to the solar energy deposited in the smoke layer, the modification of the cloud layer in response to the radiative perturbation of the smoke leads to a brightening that offsets a substantial portion of that darkening. The average radiative forcing of the entire domain for samples with OMI AI $>1$ is $-0.7 \pm 0.4 \mathrm{~W} \mathrm{~m}^{-2}$ (Fig. 7c).

It is not possible with satellite data to determine whether the cloud thickening effect depends itself on the LWP of the cloud layer. Wilcox (2010) finds that while the LWP increases with sea surface temperature over the southeast Atlantic Ocean, the difference in LWP between the high smoke 

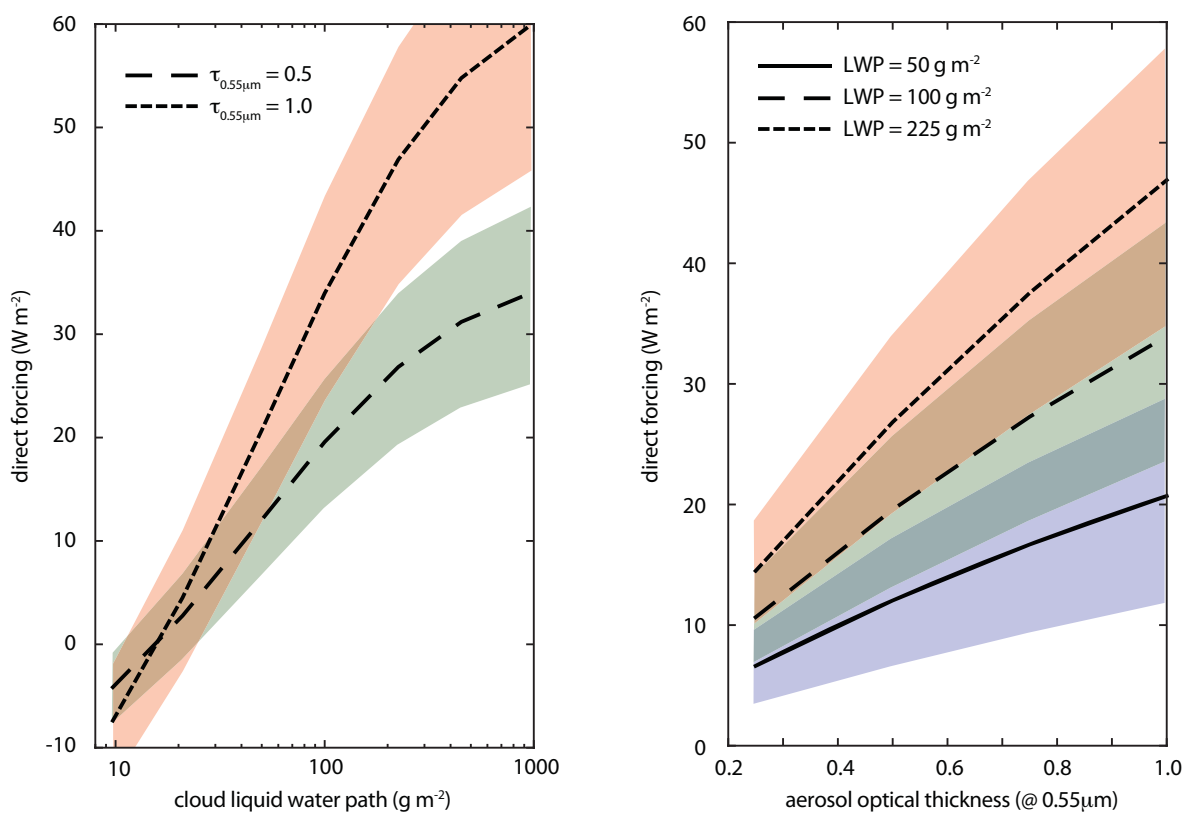

Fig. 6. (a) Direct radiative forcing determined from a radiative transfer model owing to the difference in albedo between cases of $\tau_{0.55} \mu m=0.5$ and $\tau_{0.55 \mu \mathrm{m}}=0$ (dashed), and $\tau_{0.55 \mu \mathrm{m}}=1.0$ and $\tau_{0.55 \mu \mathrm{m}}=0$ (dotted). (b) Direct radiative forcing against $\tau_{0.55 \mu \mathrm{m}}$ for clouds of LWP equal to $50 \mathrm{~g} \mathrm{~m}^{-2}$ (solid), $100 \mathrm{~g} \mathrm{~m}^{-2}$ (dashed), and $225 \mathrm{~g} \mathrm{~m}^{-2}$ (dotted). Color shaded areas bounding each line indicate range of values for \pm 0.03 uncertainty in aerosol single-scattering albedo.
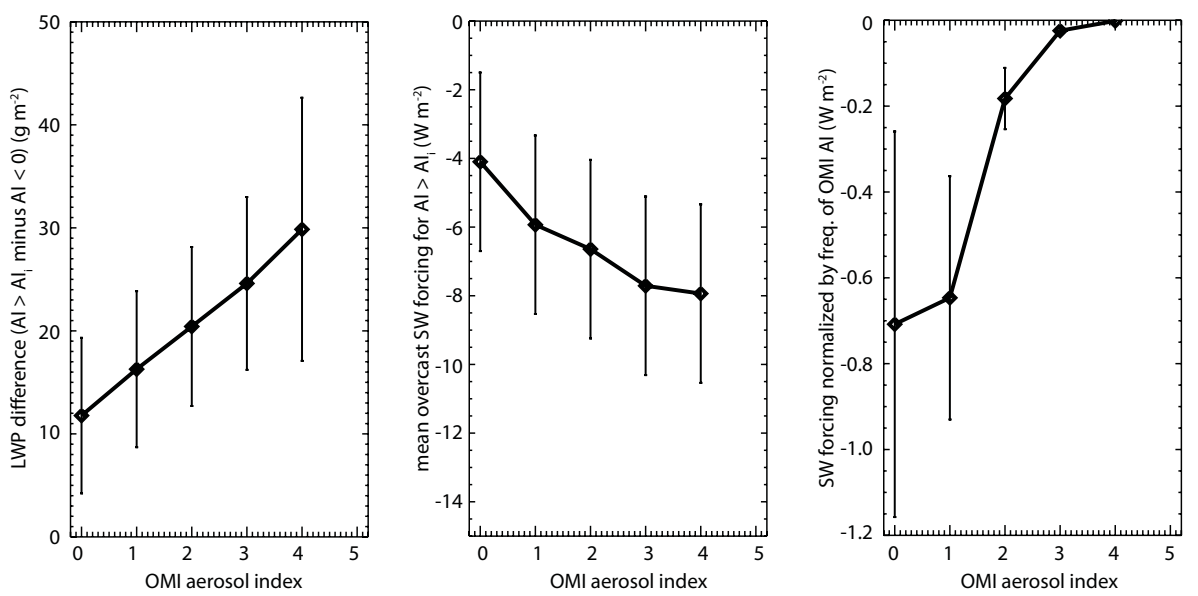

Fig. 7. (a) Difference in LWP between the average of all overcast scenes with OMI AI greater than the value on the abscissa and the average over overcast scenes with OMI AI $\leq 0$. (b) Diurnal-mean shortwave radiative forcing at the top of the atmosphere averaged over overcast scenes greater than the OMI AI value on the abscissa; and (c) the same normalized by the frequency of occurrence of OMI AI. Uncertainties are based on observed variability and instrument uncertainties (see text).

cases and low smoke cases is about $20 \mathrm{~g} \mathrm{~m}^{-2}$ regardless of SST.

In addition to the cloud thickening discussed above, semidirect cloud forcing owing to changes in the fractional coverage of cloud may also be at work over the southeast Atlantic Ocean. Positive correlations between cloud fraction and aerosol optical depth have been observed in this region in coincident MODIS satellite retrievals of aerosols and clouds (Kaufman et al., 2005; Loeb and Schuster 2008). The physical mechanism typically invoked to explain such correlations is a microphysical suppression of drizzle (Albrecht 1989). However, eliminating the confounding factors of meteorological variability and observing system artefacts causing spurious correlations in such studies remains a challenge. Loeb and Schuster (2008) show that meteorological variations evident in a model data assimilation product 
cannot explain the correlation. They note, however, that other possible explanations for the correlation require further study. Given that over $80 \%$ of CALIPSO profiles of cloud and aerosol examined by Costantino and Bréon (2010) over the region indicate that the aerosol layer and cloud layer are separated by at least $250 \mathrm{~m}$, it is perhaps appropriate to consider the possibility that the suppression of cloud-top entrainment by warming the air above the temperature inversion capping the marine boundary layer is enhancing cloud cover as well as LWP. This would provide a mechanism to explain positive correlations of aerosol optical thickness and cloud fraction in this region where the physical separation between smoke and cloud layers suggests that suppression of drizzle by aerosol-cloud interactions may not be prevalent. If true, this would contribute an additional radiative cooling attributable to the semi-direct effects of smoke over the southeast Atlantic Ocean. Offshore of California, evidence for both increases and decreases in cloud fraction associated with biomass burning aerosols were reported by Brioude et al. (2009) depending on whether simulated smoke in a chemical transport model had mixed into the boundary layer or not. Relationships between absorbing aerosols and cloud fraction are not addressed in this study. Exploring apparent correlations between cloud fraction and OMI AI is confounded by a strong dependence of retrieved UV aerosol index on cloud fraction in broken cloud scenes (Penning de Vries et al., 2009).

\section{Summary}

The stratocumulus clouds capping the marine boundary layer over the Southeast Atlantic Ocean frequently reside below an elevated layer of smoke aerosol transported offshore from the regions of African Savannah burning. This study has investigated the radiative forcing at the top of the atmosphere above overcast scenes owing to both the direct radiative effect of dark absorbing smoke aerosol above bright clouds, and the semi-direct radiative effect of thickening of cloud beneath the smoke.

The radiative effect of smoke at the top of the atmosphere may be diagnosed from the empirical relationship between cloud albedo and the cloud LWP. Cloud albedo increases strongly with increasing LWP. However, scenes with smoke above the cloud layer exhibit a lower albedo for the same value of LWP than overcast scenes without smoke above the cloud. Higher values of the OMI AI indicate greater absorption of solar radiation by smoke and coincide with lower albedos. Therefore, the direct radiative forcing of smoke above overcast scenes increases with OMI AI. The direct forcing of scenes with OMI AI $>1$ (compared to scenes with OMI AI $\leq 0$ ) is $9.2 \pm 6.6 \mathrm{~W} \mathrm{~m}^{-2}$. These scenes are sufficient to provide a climate warming over the southeast Atlantic Ocean of $1.0 \pm 0.7 \mathrm{~W} \mathrm{~m}^{-2}$ during the July to September season.
The direct radiative warming is substantially compensated by a cloud thickening effect attributable to the smoke aerosol that enhances the albedo of the cloud. Warming above the cloud layer, owing to absorption of sunlight in the smoke layer, enhances the buoyancy of free-tropospheric air above the cloud and inhibits cloud-top entrainment. This increases the LWP of clouds with OMI AI $>1$ by $16.3 \pm 7.7 \mathrm{~g} \mathrm{~m}^{-2}$, leading to a radiative cooling of $-5.9 \pm 3.5 \mathrm{~W} \mathrm{~m}^{-2}$. The enhanced LWP with increasing OMI AI values is independent of variations in SST below the cloud, and is related to warmer air above the cloud that is more likely explained by smoke aerosol heating than dynamic effects during smoke episodes over the southeast Atlantic Ocean. Thus the net radiative effect of the overcast scenes examined in this study is a small net warming, which is the result of two larger competing radiative effects.

This study has not explored possible increases in cloud fraction attributable to aerosols, which could contribute an additional cooling on average over the domain. Furthermore, higher resolution observations of LWP using visible and near-infrared retrievals (such as with the MODIS instrument) are not used in this study because they exhibit a bias in cases of thick smoke above cloud. Better estimates of the balance between the competing radiative effects of smoke over clouds for the southeast Atlantic Ocean could be attained with higher resolution observations of both cloud albedo and LWP.

Acknowledgements. This work was supported by the NASA Radiation Sciences Program and NASA grant \# NNX10AM44G. The author thanks Omar Torres and Omaira García for valuable comments. AMSR-E data are produced by Remote Sensing Systems and sponsored by the NASA Earth Science REASoN DISCOVER Project and the AMSR-E Science Team. These data are available at www.remss.com. OMI data are distributed by the Goddard Earth Sciences Data and Information Services Center. MODIS atmosphere products are distributed by the MODIS Adaptive Processing System at NASA GSFC. CERES data are distributed by the Atmospheric Science Data Center at NASA Langley.

Edited by: T. Garrett

\section{References}

Ackerman, A. S., Toon, O. B., Stevens, D. E., Heymsfield, A. J., Ramanathan, V., and Welton, E. J.: Reduction of tropical cloudiness by soot, Science, 288, 1042-1047, 2000.

Albrecht, B. A.: Aerosols, Cloud Microphysics, and Fractional Cloudiness, Science, 245, 1227-1230, 1989.

Bond, T. C.: Spectral dependence of visible light absorption by carbonaceous particles emitted from coal combustion, Geophys. Res. Lett., 28, 4075-4078, 2001.

Brioude, J., Cooper, O. R., Feingold, G., Trainer, M., Freitas, S. R., Kowal, D., Ayers, J. K., Prins, E., Minnis, P., Frost, G. J., and Hsie, E.-Y.: Effect of biomass burning on marine stratocumulus 
clouds off the California coast, Atmos. Chem. Phys., 9, 88418856, doi:10.5194/acp-9-8841-2009, 2009.

Chand, D., Anderson, T. L., Wood, R., Charlson, R. J., Hu, Y., Liu, Z., and Vaughan, M.: Quantifying above-cloud aerosol using spaceborne lidar for improved understanding of cloudysky direct climate forcing, J. Geophys. Res., 113, D13206, doi:10.1029/2007JD009433, 2008.

Chand, D., Wood, R., Anderson, T. L., Satheesh, S. K., and Charlson, R. J.: Satellite-derived direct radiative effect of aerosols dependent on cloud cover, Nat. Geosci., 2, 181-184, 2009.

Chou, M. D.: A solar radiation model for use in climate studies, J. Atmos. Sci., 49, 762-772, 1992.

Costantino, L. and Bréon, F.-M.: Analysis of aerosol-cloud interaction from multi-sensor satellite observations, Geophys. Res. Lett., 37, L11801, doi:10.1029/2009GL041828, 2010.

Eck, T. F., Holben, B. N., Ward, D. E., Mukelabai, M. M., Dubovik, O., Smirnov, A., Schafer, J. S., Hsu, N. C., Piketh, S. J., Queface, A., Le Roux, J., Swap, R. J., and Slutsker, I.: Variability of biomass burning aerosol optical characteristics in southern Africa during the SAFARI 2000 dry season campaign and a comparison of single scattering albedo estimates from radiometric measurements, J. Geophys. Res., 108, 8477, doi:10.1029/2002JD002321, 2003.

Forster, P., Ramaswamy, V., Artaxo, P., Berntsen, T., Betts, R., Fahey, D. W., Haywood, J., Lean, J., Lowe, D. C., Myhre, G., Nganga, J., Prinn, R., Raga, G., Schulz, M., and Van Dorland, R.: Changes in Atmospheric Constituents and in Radiative Forcing. In: Climate Change 2007: The Physical Science Basis. Contribution of Working Group I to the Fourth Assessment Report of the Intergovernmental Panel on Climate Change, edited by: Solomon, S., Qin, D., Manning, M., Chen, Z., Marquis, M., Averyt, K. B., Tignor, M., and Miller, H. L., Cambridge University Press, Cambridge, UK and New York, NY, USA, 2007.

Hansen, J., Sato, M., and Ruedy, R.: Radiative forcing and climate response. J. Geophys. Res., 102, 6831-6864, 1997.

Haywood, J. M., Francis, P., Dubovik, O., Glew, M., and Holben, B.: Comparison of aerosol size distributions, radiative properties, and optical depths determined by aircraft observations and Sun photometers during SAFARI 2000, J. Geophys. Res., 108, 8471, doi:10.1029/2002JD002250, 2003.

Haywood, J. M., Osborne, S. R., and Abel, S. J.: The effect of overlying absorbing aerosol layers on remote sensing retrievals of cloud effective radius and cloud optical depth, Q. J. Roy. Meteorol. Soc., 130, 779-800, 2004.

Herman, J. R., Bhartia, P. K., Torres, O., Hsu, C., Seftor, C., and Celarier, E.: Global distribution of UV-absorbing aerosols from Nimbus 7/TOMS data, J. Geophys. Res., 102, 16911-16922, 1997.

Hsu, N. C., Herman, J. R., Bhartia, P. K., Seftor, C. J., Torres, O., Thompson, A. M., Gleason, J. F., Eck, T. F., and Holben, B. N.: Detection of biomass burning smoke from TOMS measurements, Geophys. Res. Lett., 23, 745-748, 1996.

Johnson, B. T., Shine, K. P., and Forster, P. M.: The semi-direct aerosol effect: Impact of absorbing aerosols on marine stratocumulus, Q. J. Roy. Meteorol. Soc., 130, 1407-1422, 2004.

Kaufman, Y. J., Koren, I., Remer, L. A., Rosenfeld, D., and Rudich, Y.: The effect of smoke, dust, and pollution aerosol on shallow cloud development over the Atlantic Ocean, Proc. Natl. Acad. Sci., 102, 11207-11212, 2005.
Kaufman, Y. J. and I. Koren (2006), Smoke and Pollution Aerosol Effect on Cloud Cover, Science, 313 655-658, DOI: 10.1126/science. 1126232 .

Loeb, N. G., Kato, S., Loukachine, K., Manalo-Smith, N., and Doelling, D. R.: Angular distribution models for top-ofatmosphere radiative flux estimation from the Clouds and the Earth's Radiant Energy System instrument on the Terra satellite. Part II: Validation, J. Atmos. Ocean. Technolo., 24, 564-584, 2007.

Loeb, N. G. and Schuster, G. L.: An observational study of the relationship between cloud, aerosol and meteorology in broken low-level cloud conditions, J. Geophys. Res., 113, D14214, doi:10.1029/2007JD009763, 2008.

Penning de Vries, M. J. M., Beirle, S., and Wagner, T.: UV Aerosol Indices from SCIAMACHY: introducing the SCattering Index (SCI). Atmos. Chem. Phys., 9, 9555-9567, doi:10.5194/acp-99555-2009, 2009.

Peters, K., Quaas, J., and Bellouin, N.: Effects of absorbing aerosols in cloudy skies: a satellite study over the Atlantic Ocean. Atmos. Chem. Phys., 11, 1393-1404, 2011, http://www.atmos-chem-phys.net/11/1393/2011/.

Platnick, S., King, M. D., Ackerman, A., Menzel, W. P., Baum, B. A., Riédi, J. C., and Frey, R. A.: The MODIS cloud products: Algorithms and examples from Terra, IEEE Trans. Geosci. Remote Sens., 41, 459-473, 2003.

Podgorny, I. A. and V. Ramanathan: A modeling study of the direct effect of aerosols over the tropical Indian Ocean, J. Geophys. Res., 106, 24097-24105, 2001.

Ramanathan, V., Crutzen, P. J., Kiehl, J. T., and Rosenfeld, D.: Aerosols, climate, and the hydrological cycle, Science, 294, 2119-2124, 2001.

Russell, P. B., Bergstrom, R. W., Shinozuka, Y., Clarke, A. D., DeCarlo, P. F., Jimenez, J. L., Livingston, J. M., Redemann, J., Dubovik, O., and Strawa, A.: Absorption Angstrom Exponent in AERONET and related data as an indicator of aerosol composition, Atmos. Chem. Phys., 10, 1155-1169, doi:10.5194/acp10-1155-2010, 2010.

Swap, R., M. Garstang, S. A. Macko, P. D. Tyson, W. Maenhaut, P. Artaxo, P. Kållberg, and R. Talbot: The long-range transport of southern African aerosols to the tropical South Atlantic, J. Geophys. Res., 101, 23777-23791, 1996.

Torres, O., Bhartia, P. K., Herman, J. R., Ahmad, Z., and Gleason, J.: Derivation of aerosol properties from satellite measurements of backscattered ultraviolet radiation: Theoretical basis, J. Geophys. Res., 103, 17099-17110, 1998.

Torres, O., Tanskanen, A., Veihelmann, B., Ahn, C., Braak, R., Bhartia, P. K., Veefkind, P., and Levelt, P.: Aerosols and surface UV products from Ozone Monitoring Instrument observations: An overview, J. Geophys. Res., 112, D24S47, doi:10.1029/2007JD008809, 2007.

Torres, O., Jethva, H., and Bhartia, P. K.: Retrieval of aerosol optical depth above clouds from OMI observations: Sensitivity analysis and case studies, J. Atmos. Sci., doi:10.1175/JAS-D-110130.1, in press, 2011.

Waquet, F., Riedi, J., Labonnote, L. C., Goloub, P., Cairns, B., Deuze, J.-L., and Tanre, D.: Aerosol remote sensing over clouds using A-Train observations, J. Atmos. Sci., 66, 2468-2480, 2009. 
Wentz, F. J.: A well-calibrated ocean algorithm for Special Sensor Microwave/Imager, J. Geophys. Res., 102, 8703-8718, 1997.

Wentz, F. J. and Spencer, R. W.: SSM/I rain retrievals within a unified all-weather ocean algorithm, J. Atmos. Sci., 55, 1613-1627, 1998.

Wielicki, B. A., Barkstrom, B. R., Harrison, E. F., Lee, R. B. III, Smith, G. L., and Cooper, J. E.: Clouds and the Earth's Radiant Energy System (CERES): An Earth Observing System Experiment, B. Am. Meteorol. Soc., 77, 853-868, 1996.
Wilcox, E. M., Harshvardhan, and Platnick, S.: Estimate of the impact of absorbing aerosol over cloud on the MODIS retrievals of cloud optical thickness and effective radius using two independent retrievals of liquid water path, J. Geophys. Res., 114, D05210, doi:10.1029/2008JD010589, 2009.

Wilcox, E. M.: Stratocumulus cloud thickening beneath layers of absorbing smoke aerosol. Atmos. Chem. Phys., 10, 1176911777, doi:10.5194/acp-10-11769-2010, 2010.

Wild, M.: Global dimming and brightening: A review, J. Geophys. Res., 114, D00D16, doi:10.1029/2008JD011470, 2009. 